\title{
Effective ways to deliver sustainability in urban and regional landscape strategies
}

\author{
A. Nikologianni1,a, K. Moore ${ }^{1}$ and P. Larkham ${ }^{2}$ \\ 1School of Architecture and Design, Birmingham City University, UK \\ ${ }^{2}$ School of Engineering and the Built Environment, Birmingham City University, UK
}

\begin{abstract}
This paper argues that, in order to deliver sustainable urban and regional landscapes, an integrated approach of individual elements such as legislations, design thinking and biodiversity needs to be considered. It forms part of a wider research project, examining the extent to which low carbon and sustainability can be delivered effectively in landscape strategies, which covers examples from the 'Landscape Observatory' (Spain), the 'Room for the River' and 'New Dutch Waterline' (Netherlands) and the 'HS2LV' project (UK). The Netherlands case study, presented in this paper, consisted by two large scale landscape projects is used to illustrate this approach. The 'Room for the River' and the 'New Dutch Waterline' are used to demonstrate how the idea of landscape, low carbon and design quality can shape the effective implementation of landscape strategies. Key elements and effective ways of delivering sustainable places have been identified through a series of real time visits, interviews and observations. The development of procurement processes, legislation, and understanding of the role of landscape sustainability and landscape quality as well as the importance of spatial representation of these ideas will be presented and discussed in order to illustrate a sustainable holistic approach and the tremendous impact that this has on the landscape and the region.
\end{abstract}

Keywords: landscape design, low carbon, spatial quality, aesthetics, climate adaptation, climate change

\section{INTRODUCTION}

This paper forms part of a wider research project investigating ways in which low carbon and spatial quality can be delivered in regional strategies. The aims of the broader research are to examine how the concepts of low carbon and spatial quality are used to regional design, the way such ideas can influence the decision makers and how they might impact up on the implementation of infrastructure. Three pioneer landscape projects in Spain (the 'Landscape Observatory'), the Netherlands (the 'Room for the River' /'New Dutch Waterline') and the UK ('HS2/HS2LV') have been selected as case studies. This paper solely focuses on the implementation stage, examining the extent to which low carbon and sustainability can be effectively embedded in landscape strategies and how does this impact on the landscape and the region. The paper argues that low carbon and sustainability are broader concepts that relate to our way of life and not just technological or scientific artefacts. Arguing that it is their spatial dimension that is very difficult to be recognised, this research will present findings on how such ideas can be integrated in landscape projects. 'Sustainability is today one of the most widely used words in the scientific field as a whole and in the environmental sciences in particular, but the analysis of the evolution of such a concept is a difficult exercise' (Leal Filho, 2000). The latest literature argues that the concepts of low-carbon and sustainability have been widely advocated, however there is a lack of an in-depth examination and understanding of the similarities and the differences among them (Yuan et al., 2011) and therefore there is a variety for interpretations for low

\footnotetext{
a E-mail: anastasia.nikologianni@mail.bcu.ac.uk
} 
carbon development (Baeumler et al., 2012; Mulugetta and Urban, 2010). Recent literature has challenged the interpretation of low carbon and sustainable areas, questioning if this is based on activities, lifestyles and voluntary behaviour change or policy frameworks that are based on regulatory force (Feliciano and Prosperi, 2011). There is much activity on examples focusing on sustainable technology placed in the landscape, but there is less written for a holistic approach. As a result landscape is considered to be the 'space' where the sustainable activities will take place, rather than the 'place' that will be created and be part of a sustainable regional development. Examining pioneer landscape projects, this paper illustrates the potential of introducing low carbon and quality of space as a vital aspect of regional landscape strategies.

\section{METHODOLOGY}

The focus at this point is to investigate the operations and climate change aspects of the large landscape strategies that belong to the framework of sustainable development.

The 'Room for the River' is an excellent illustration of climate driven regional landscape design, implemented to address the problem of serious flooding now and in the future in the Netherlands due to increased rainfall and rising sea levels (Figure 1). It is a national programme, aiming to achieve high water level protection in 34 locations across the Netherlands, having a holistic approach about climate issues and sustainability that put landscape at the core of development without minimizing the quality of life. The uniqueness of a landscape adaptation programme looking into water safety, but also addressing spatial quality issues, the large scale that it was carried, the goals for long-term sustainability and the way that Dutch institutions dealt with its implementation, are considered pioneering in the current landscape and made it an ideal case study for the purposes of this research.

The 'New Dutch Waterline' is a national landscape programme consisted by approximately 60 different fortresses across the Netherlands (Figure 2). It was originally designed in the $19^{\text {th }}$ century as a military defence system able to enable controlled inundation through sophisticated landscape engineering.

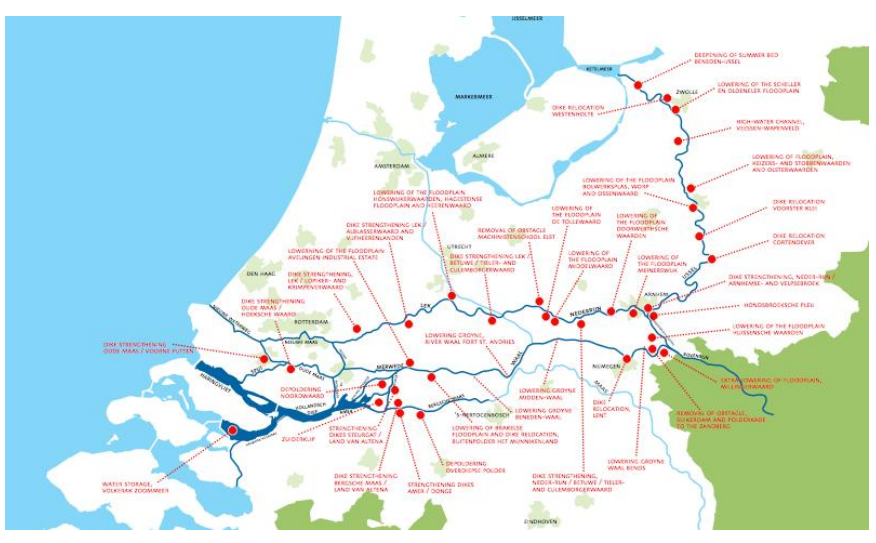

Figure 1. Map showing the location of the 34 different landscape projects of the 'Room for the River' programme (Source: Ruimte voor de rivier official organisation).

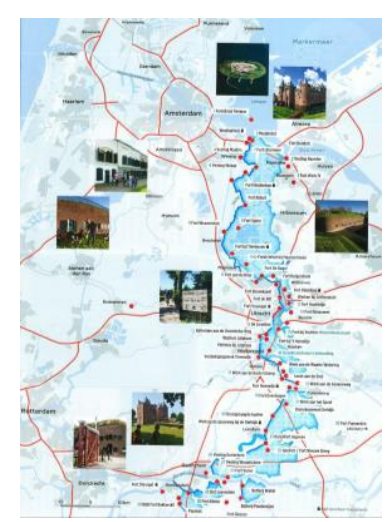

Figure 2. Map showing the locations of 'New Dutch Waterline' Programme (Source: Hollandse Waterlinie official organisation).

For a period of one month the researcher was hosted by the University of Delft and examined the landscape programmes of the 'Room for the River' and the 'New Dutch Waterline'. Investigation of the overall concept of the projects and the decision to implement landscape sustainability and spatial quality in such a large scale was the initial focus of the case study. The main research body consists of visits to the locations of specific landscape 
projects offering the opportunity to work, observe and interview designers and experts from both programmes.

The research methods used include field visits, interviews, observations and drawing examination in order to find out how the landscape ideas, low carbon and spatial quality concepts have been implemented. During the field visits at the landscape projects the researcher was able to observe, collect plans and maps of the area, take pictures and interview key stakeholders. Face to face interviews with experts, project managers and technicians who were highly involved at the schemes were conducted.

\section{RESULTS AND DISCUSSION}

Based on data collected during the field visits, interviews and observations, this research is arguing that there is a lack of clarity and high variability of the low carbon and sustainability terms in the landscape context, and therefore there is no clear understanding of their interpretation or spatial context. Findings emerging from the field visits and interviews show that these terms are ambiguous and amorphous and they are also very confusing to those who are not familiar or have not dealt with them before. However, examples of the pioneer projects investigated show that is possible to deliver sustainable and quality landscape projects, the way this has been achieved and what it looks like.

The challenges with the concepts of low carbon and spatial quality might occur because of their variability between disciplines, landscape projects and countries. This research indicates that a major proportion of professionals believe that low carbon and sustainability for the landscape is only something that it has to do with Carbon. Either this is carbon neutral, low carbon, carbon cycle or materials, energy, $\mathrm{CO}_{2}$ emissions, transport and more. Based on data collected on the question 'what do you understand is meant by the term low carbon in the landscape', the research shows that there is no unanimous agreement between the experts, neither does exist a common understanding about what is the spatial role of those ideas. Two notions were identified during the interviews. The first is aligning with the literature evidence by stating that low carbon has to do with a technological, scientific or numerical process while the second is exploring more holistic ideas that combine sustainability and quality of place. The collected data do not only urge the variability of these concepts between the different disciplines, but also among the level of expertise and the familiarity of the term in different countries.

This research suggests that when the concepts of low carbon and spatial quality are integrated and considered equally important to a landscape scheme, is much more likely to achieve a sustainable and quality space. It was relatively recent when Pickerill (2010), discussing about liveable cities and low impact development, argued that 'we need to look beyond technological innovation for solutions' in this area. And it is this point that aligns with our findings giving the opportunity to interpret low carbon and spatial quality in a much broader context. What has been found is that they often need to be analysed in different ways or with slightly different spatial characteristics that align with the project, the location and the culture. Interview data and case study observations suggest that a sophisticated process is required in cases of regional strategies in order to find ways of identifying the landscape quality and low carbon in a spatial context. What this research proposes is that we need to accept that the discussed concepts are complex and confusing, however extremely important for landscape design. During the Netherlands case study it was found that a specific meaning of low carbon and spatial quality was developed by the landscape strategy of the Room for the River. Climate adaptation and water levels are very much linked with low carbon and sustainability and they were the first goal of this programme, aiming to address water safety. It is indeed showing that one way to deal with such ideas is to interpret them for the specific location and the landscape project. There is no doubt that this interpretation should align with some of the main concepts and 
definitions that the terms belong to, but what is argued here is that the spatial dimension of such terms might change from location to location.

In addition, the New Dutch Waterline was aiming to address sustainability, in a different way to the Room for the River, by preserving and improving the existing land around the fortresses. Spatial quality was also a significant element in this scheme, but it was identified as an idea of preservation, cultural enlightenment, touristic opportunity and celebration of the historic legacy. Therefore the interpretation of the low carbon and spatial quality concepts were slightly different, aligning with a different vision. However, both schemes have resulted in successful sustainable landscape projects.

\section{Make the vision clear}

It is indeed a great challenge to make the vision of a low carbon and quality landscape clear and communicate these ideas to the broader audience. Case study findings and interviews have shown that even in cases where these concepts are identified for a specific landscape scheme it is difficult to make them visible and give them a 'tangible' or 'physical' substance. But this research agrees with Lutz (2008) who argues that 'it ought to be possible to describe what it is that makes a space attractive'. This paper suggests that the most effective visions are conveyed through design and drawing; and, therefore, design thinking is an important way to interpret how these complex concepts are spatially represented and what they 'look like' in the landscape. At one of the examples of the Room for the River, the urban project in Nijmegen and Lent, low carbon and sustainability were identified as water safety and environmental stability. However the dyke relocation that was developed by the scheme (Figure 3) was a great opportunity for the development of a peninsula and two new waterfronts for the city. The understanding and communication of the low carbon and landscape quality concepts among the different project teams resulted in a sustainable and aesthetic place, with great social, cultural, touristic and economic value. Design and drawing played a great role in this successful outcome, as through them these intangible concepts could be better 'seen' and understood.
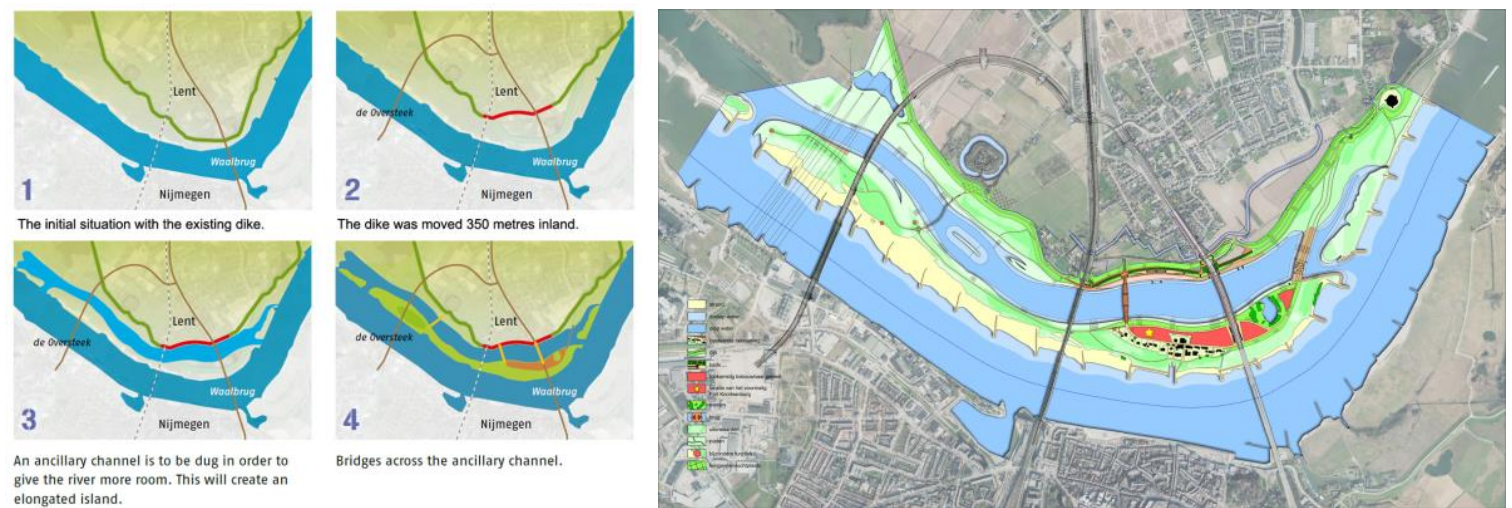

Figure 3: On the left, the dyke relocation in Lent and the creation of a new peninsula for the city of Nijmegen, one of the projects of the Room for the River Programme. On the right the final plan of the project (Source: city of Nijmegen).

Visualisations such as those presented here (Figure 4) are showing how a low carbon and environmental area can also provide quality of space, cycling, social activities and more. A different interpretation of sustainability and spatial quality has been given at the rural project of the Room for the River in Noordwaard. Noorwaard is an agricultural area that floods at various times. The project was aiming to celebrate nature and offer various activities to locals and visitors.

In the rural Noordwaard project dykes were relocated and specific inundation areas were created. Sustainability for this scheme is not expressed by avoiding the water, but by 
creating areas where it could find room, when at the same time highly environmental and quality spaces will be introduced. In a different way to the urban project of Nijmegen, the Noordwaard scheme is a rural location where nature should be preserved. Therefore quality elements such as materials, plants and observation areas were introduced in order to improve spatial quality and create an attractive place. The willow forest shown in Figure 5 belongs to the concept 'Building with nature' developed by the designing team of the project. It was especially designed as flood protection, but also gives the opportunity to build a lower height dyke in order to enhance aesthetics of place. The willow trees are planted in lines in such direction that reduce the waves the best possible way and they also belong to two different species in case one of them is affected and destroyed.
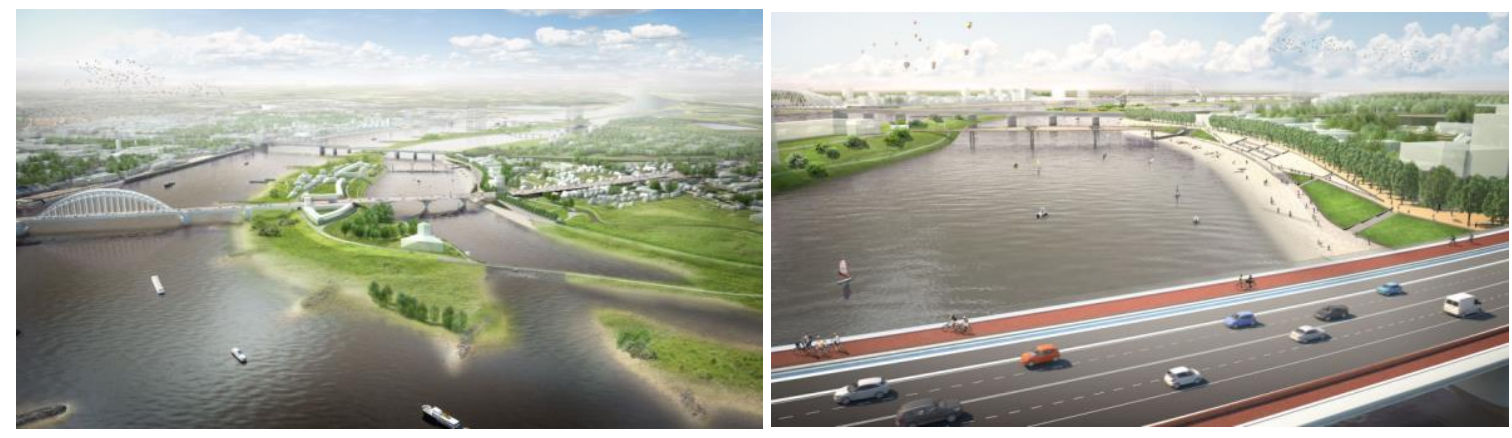

Figure 4: Visualisations of the Nijmegen project, Room for the River presenting a sustainable vision for the city (Source: city of Nijmegen).

Aiming at preservation of historical sites as well as the creation of new uses, the programme of the New Dutch Waterline has 'redesigned' and transformed a series of old fortresses into areas of cultural restoration, touristic sites, entertainment venues and natural areas. Having developed projects like the Bunker 599 and the Fort Werk aan't Spoel (Figure 6), is giving the opportunity to locals and visitors to find out about national history, while the same time enjoying a sustainable and beautiful landscape.

\section{CONCLUSIONS}

Findings show that successful delivery requires the development of a vision and the understanding of the low carbon and spatial quality concepts through design in order to be implemented on the infrastructure. The establishment of a sophisticated process based on good understanding of the role of landscape is essential for the delivery of these concepts in urban and regional schemes. Data emerging from the pioneer projects show that the design vision should recognise sustainability and sense of place as intertwined ideas that need to be addressed in regional design. However, it is possible for them to be expressed visually in various ways creating different landscape areas.

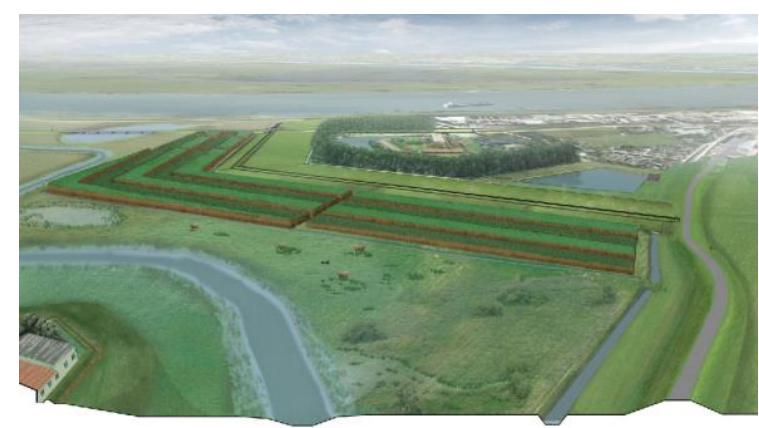

Figure 5: The willow forest of Noordwaard Project, Room for the River. (Source: Robert de Konning, landscape architect of the scheme). 
One of the key findings is that some of the most effective visions are often conveyed through drawings and therefore design is playing a major role in the delivery of such complex concepts. Strong communication, collaboration and continuous involvement of the designers have been proven essential and similar management processes are strongly suggested for strategic projects. The development of procurement processes, policies and legislations as part of the administration phase of regional landscape schemes are also considered necessary for future landscape strategies.
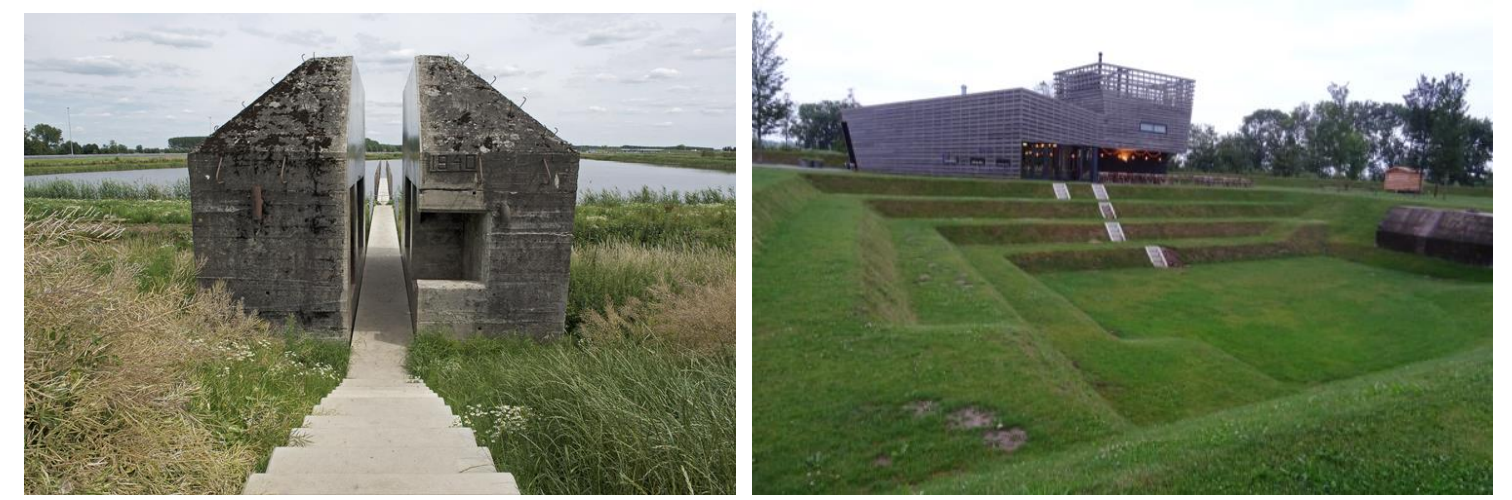

Figure 6: Designed by Atelier de Lyon and RAAAF the open 'Bunker 599' was aiming to make visible and accessible an important part of Dutch history (left). The Fort Werk aan't Spoel has been recreated to a unique area aiming for entertainment (right).

\section{ACKNOWLEDGEMENTS}

The authors want to thank Climate-KIC, for their support in this research, as well as all the participants at the Room for the River and the New Dutch Waterline schemes.

\section{Literature cited}

Baeumler, A., Ijjasz-Vasquez, E., and Mehndiratta, S. (2012). Sustainable low-carbon city development in China, World Bank Publications. 10.1596/978-0-8213-8987-4.

Feliciano, M., and Prosperi, D.C. (2011). Planning for low carbon cities: Reflection on the case of Broward County, Florida, USA: Low Carbon Cities. (45th ISOCARP World Congress Porto, Portugal 18-22 October 2009), v. 28, p. 505-516. http://dx.doi.org/10.1108/1467630010307066.

Leal Filho, W. (2000). Dealing with misconceptions on the concept of sustainability. International journal of sustainability in higher education, v. 1, p. 9-19. http://dx.doi.org/10.1108/1467630010307066.

Lutz, S., (2008). Shared Space, Spatial Quality Places that attract people, in F. Province, ed., Groningen PlantijnCasparie, Groninge.

Mulugetta, Y., and Urban, F. (2010). Deliberating on low carbon development. Energy Policy, v. 38, p. 7546-7549. http://dx.doi.org/10.1016/j.enpol.2010.05.049.

Pickerill, J. (2010). Building liveable cities: urban Low Impact Developments as low carbon solutions?: Cities and low carbon transitions, Routledge, London.

Yuan, H., Zhou, P., and Zhou, D. (2011). What is Low-Carbon Development? A Conceptual Analysis: 2010 International Conference on Energy, Environment and Development - ICEED2010, v. 5, p. 1706-1712. http://dx.doi.org/10.1016/j.egypro.2011.03.290. 